\title{
Effect of Referral Patterns and Treatment Type on Oncologic Outcomes for Women with Ductal Carcinoma In Situ
}

Elaine S. Wai ${ }^{1}$, Mary Lesperance ${ }^{2}$, Linghong $\mathrm{Lu}^{3}$, Cheryl S. Alexander ${ }^{4}$, Pauline T. Truong ${ }^{5}$

1. Radiation Oncology, University of British Columbia, BC Cancer Agency 2. Oncology, University of Victoria, Victoria, CAN 3. Statistics, University of Victoria 4. BC Cancer Agency 5. Radiation Oncology, British Columbia Cancer Agency - Vancouver Island Centre, Victoria, CAN

$\square$ Corresponding author: Pauline T. Truong, ptruong@bccancer.bc.ca Disclosures can be found in Additional Information at the end of the article

\section{Abstract \\ Objective}

Management of ductal carcinoma in situ (DCIS) remains controversial. This study examined long-term outcomes in a population-based cohort of patients with pure DCIS treated with breast-conserving surgery (BCS) alone, BCS + radiotherapy (RT), and mastectomy. Outcomes were compared between patients referred versus not referred for oncologic assessment after definitive surgery.

\section{Materials and methods}

Subjects were 2575 women diagnosed between 1985 and 1999. Data from several electronic databases were linked and analyzed. Outcomes were invasive local recurrence-free survival (ILRFS), mastectomy-free survival (MFS), breast cancer-specific survival (BCSS), and overall survival (OS).

\section{Results}

Median follow-up time was 9.8 years. Overall, 56\% $(n=1448)$ of subjects were referred to a cancer centre. Factors associated with non-referral were older age, comorbidities, and travel distance. Ten-year MFS, BCSS, and OS were higher among referred patients (all $p \leqslant 0.001)$. In cohorts treated with BCS alone $(n=1314)$ vs. BCS + RT $(n=510)$ vs. mastectomy $(n=751), 10-$ year ILRFS were 93.7\% vs. 96.6\% vs. 97.7\%, (p < 0.001) and BCSS were 97.6\% vs. 99.8\% vs. 98.6\%, $(\mathrm{p}=0.01)$. Corresponding rates of ipsilateral invasive breast relapse at 10 years were $6.3 \%$ after BCS alone, 3.4\% after BCS + RT, and 2.3\% after mastectomy ( $<$ 0.001). On multivariable analysis, factors associated with improved ILRFS were older age at diagnosis, low comorbidity score, absence of comedo histology, mastectomy, and post-BCS RT.

Received 02/23/2017

Review began 03/09/2017 Review ended 03/28/2017 Published 03/31/2017

(c) Copyright 2017

Wai et al. This is an open access article distributed under the terms of the Creative Commons Attribution License CC-BY 3.0., which permits unrestricted use, distribution, and reproduction in any medium, provided the original author and source are credited.

\section{Conclusion}

Patients with DCIS referred for oncologic assessment were more likely to undergo post-BCS RT, resulting in lower mastectomy and higher survival rates compared to non-referred patients. Patients with significant comorbidities were less likely to be referred and experienced lower ILRFS and BCSS. Referral for multidisciplinary oncologic assessment after surgery is warranted to individualize management and optimize outcomes for patients with DCIS.

How to cite this article

Wai E S, Lesperance M, Lu L, et al. (March 31, 2017) Effect of Referral Patterns and Treatment Type on Oncologic Outcomes for Women with Ductal Carcinoma In Situ. Cureus 9(3): e1128. DOI 10.7759/cureus. 1128 
Categories: Radiation Oncology, General Surgery, Oncology

Keywords: ductal carcinoma in situ, breast cancer, mastectomy, radiation therapy, breast conservation, local recurrence, outcomes, prognostic factors, referral

\section{Introduction}

Ductal carcinoma in situ (DCIS) comprises approximately 20-30\% of mammographically detected breast cancers [1]. Management of DCIS has been the subject of randomized trials, prospective series, and retrospective reviews [2-12]. Diverse treatment strategies exist, including breast conserving surgery (BCS) alone, BCS plus radiotherapy (RT), or mastectomy, showing similar breast cancer-specific survival [2-12]. While there are no randomized trials directly comparing mastectomy to breast-conserving therapy in women with pure DCIS, the management of DCIS has evolved over time towards the increased use of breast conserving therapy for the majority of patients diagnosed in contemporary practice [10].

Among women who undergo BCS, randomized trials have shown that RT significantly reduces invasive and in-situ recurrence [2-3]. Prospective studies evaluating outcomes in patients treated with BCS alone have reported varied results [4-5]. Guidelines from the National Health Institute and American College of Radiology support consideration of BCS + RT or mastectomy as effective local therapies for most patients with DCIS and advocate continued research to evaluate the question of whether there are subsets with sufficiently low risk who may be treated with BCS alone [8-9].

While DCIS is a highly curable disease, invasive local recurrences can compromise survival [1315]. Despite randomized trials demonstrating local control benefits with RT after BCS, the use of RT varies widely at the population level [15]. In addition, even though evidence-based guidelines advocate multidisciplinary evaluation for patients with DCIS [7-9] and quality indicators have been developed to monitor population-based treatment [14], disparities in care delivery among different populations are still documented [15]. These findings raise questions regarding whether variations among community physicians in referring patients for oncologic assessment after diagnosis may impact treatment and outcomes for women with DCIS.

The British Columbia Cancer Agency (BCCA) is a provincial organization that operates six regional cancer centres (four during the study era), to serve a population of approximately 4 million people. It provides $100 \%$ of the RT and manages the budget for all antineoplastic drugs in British Columbia (BC). Women diagnosed with breast cancer are typically seen by surgeons for definitive surgery, then referred to one of the regional cancer centres if felt necessary by the surgeon or family physician for a discussion of adjuvant therapy. Patients unsure of which initial surgery to pursue or patients with challenging management decisions may also be referred for review prior to surgery.

The primary objectives of the current study were to compare differences in baseline characteristics and outcomes among women with DCIS according to referral status and treatment. The secondary objectives were to identify factors associated with ipsilateral invasive local recurrence and breast cancer-specific survival.

\section{Materials And Methods}

\section{Study subjects}

A retrospective study was conducted of 2575 women with newly diagnosed pure DCIS between January 1, 1985 and December 31, 1999, treated in the province of British Columbia, Canada. Exclusion criteria were concomitant or previous invasive cancer of any site, or contralateral DCIS predating the index diagnosis. 


\section{Data sources}

Cases were identified using the $\mathrm{BC}$ Cancer Registry. These data were linked to electronic files from the Screening Mammography Program of BC (SMPBC), the Hospital Separation File/Discharge Abstract Database, Vital Statistics Agency, Ministry of Health, Government of British Columbia, and the BCCA Breast Cancer Outcomes Unit. The SMPBC database, which contains demographic, prognostic, and initial treatment information on all women screened since 1988, maintains active follow-up to ascertain the final pathology results to identify all screen-detected and interval cancers. The Hospital Separation File/Discharge Abstract Database File contains data from discharge summaries of all hospitalizations and day surgeries in BC. The BC Ministry of Health and Vital Statistics owns and has approved access and use of the data facilitated by Population Data BC for this study. For patients diagnosed between 1985 and 1988, there was no SMPBC data to supplement the other data sources.

\section{Study setting and institutional guidelines}

The BCCA database prospectively collects demographic, clinicopathologic, treatment, and outcomes data for all women with newly diagnosed in situ or invasive breast cancer referred for management. Central pathology review was available by request of the treating oncologist. If not requested, pathology was reported by pathologists in the community or at academic centres in Vancouver or Victoria.

Institutional management guidelines for DCIS were available and regularly updated by the interdisciplinary Breast Tumour Group, comprised of all surgeons, radiation oncologists, and medical oncologists treating breast cancer at the BCCA. In the early years of the study, a high proportion of patients with DCIS underwent mastectomy. BCS was advised if the DCIS was unifocal, without comedo histology, and the patient was suitable for follow-up (clinical exam and mammogram "easy to interpret"). In 1993, following the publication of the NSABP B17 study, provincial guidelines were updated to recommend adjuvant breast RT after BCS for patients with DCIS $>1 \mathrm{~cm}$, comedocarcinoma, or margins $<5 \mathrm{~mm}$. Women with welldifferentiated DCIS $<1 \mathrm{~cm}$ and clear margins $>5 \mathrm{~mm}$ were generally managed by wide excision alone. Women with diffuse DCIS ( $>5 \mathrm{~cm}$ or $>1 / 4$ of the breast on mammogram) were recommended to undergo mastectomy. Tamoxifen was not recommended during the study era outside of available clinical trials. Provincial follow-up guidelines recommended history and physical exam by a physician every three-six months for the first five years, then annually, with annual mammography.

\section{Outcomes analysis}

Primary outcomes were ipsilateral invasive local recurrence-free survival (ILRFS) and breast cancer-specific survival (BCSS). Secondary outcomes were mastectomy-free survival (MFS), and overall survival (OS). Chi-square tests were used to compare clinicopathologic and treatment characteristics among cohorts treated with BCS alone $(n=1314)$, BCS + RT $(n=510)$, and mastectomy $(n=751)$; and among cohorts who were referred $(n=1448)$ versus not referred $(n=$ 1127) for oncologic assessment after definitive surgery. Kaplan-Meier (KM) estimates and logrank tests were used to compare survival outcomes by treatment type and by referral status. Multivariable Cox regression analysis was performed to assess predictors of ILRFS and BCSS. Factors included in the multivariable model included age, referral to BCCA status, DeyoCharlson Comorbidity score [16], nuclear grade, size of primary tumour, margin status, comedo histology, and initial treatment. Estrogen receptor (ER) status was not included in the Cox modeling because testing for ER was not routine during the study era. Necrosis was not included because comedonecrosis was included independently in the histology code, and a large number of cases had unknown values for necrosis. 


\section{Cureus}

The study was approved by the BCCA Research Ethics Board.

\section{Results}

Median follow-up time was 9.8 years. Overall, 10-year ipsilateral invasive breast relapse was $4.5 \%$ and BCSS was $98.3 \%$.

\section{Comparisons of clinical characteristics and outcomes by referral status}

Overall, 1448 (56\%) women were referred to BCCA after primary surgery. Referral rates consistently approximated 50\% from 1985 until 1996, after which referral rates gradually increased from $57 \%$ in 1996 to $69 \%$ in 1999 . Referred patients were more likely to be younger at diagnosis, live within two hours from the nearest cancer centre at the time of diagnosis, and have lower comorbidity scores (Table 1).

Multivariable analysis showed referral status was associated with age, Deyo-Charlson comorbidity scores, and residence $>2$ hours from the nearest cancer centre at the time of diagnosis. Those less likely to be referred had a higher incidence of unknown grade, lesion size, and margin status. Those with comedocarcinoma were more likely to be referred.

Among women who were not referred, the majority (75\%) underwent BCS alone while $24 \%$ underwent mastectomy. Among women who were referred, treatment type was evenly divided among the three groups (Table 1).

\begin{tabular}{|c|c|c|c|c|c|c|c|c|c|}
\hline & & $\begin{array}{l}\text { All } \\
\text { patients } \\
(n= \\
2575)\end{array}$ & $\begin{array}{l}\text { Referred to } \\
\text { BCCA (n = } \\
1448)\end{array}$ & $\begin{array}{l}\text { Not } \\
\text { referred } \\
(n=1127)\end{array}$ & $\begin{array}{l}p- \\
\text { value }\end{array}$ & $\begin{array}{l}\text { BCS } \\
\text { alone } \\
(n= \\
1314)\end{array}$ & $\begin{array}{l}\text { BCS + } \\
\text { RT } \\
(n= \\
510)\end{array}$ & $\begin{array}{l}\text { Mastectomy } \\
\quad(n=751)\end{array}$ & $\begin{array}{l}p- \\
\text { value }\end{array}$ \\
\hline & & $\mathrm{n}(\%)$ & n (\%) & n (\%) & & n (\%) & n (\%) & n (\%) & \\
\hline \multicolumn{10}{|c|}{ Age (years) } \\
\hline & $<50$ & 757 (29) & 484 (33) & $273(24)$ & $<0.001$ & $346(26)$ & $\begin{array}{l}161 \\
(32)\end{array}$ & 250 (33) & $<0.001$ \\
\hline & $50-59$ & $65 /(26)$ & $396(27)$ & $261(23)$ & & $321(24)$ & $\begin{array}{l}170 \\
(33)\end{array}$ & $166(22)$ & \\
\hline & $60-69$ & $620(24)$ & 336 (23) & $284(25)$ & & 312 (24) & $\begin{array}{l}111 \\
(22)\end{array}$ & 197 (26) & \\
\hline & $\geq 70$ & $541(21)$ & 232 (16) & 309 (27) & & $335(26)$ & $68(13)$ & 138 (18) & \\
\hline & Median & 57 & 55 & 61 & & 59 & 55 & 57 & \\
\hline \multirow[t]{2}{*}{$\begin{array}{l}\text { Referral } \\
\text { status }\end{array}$} & Referred & & & & & 461 (35) & $\begin{array}{l}510 \\
(100)\end{array}$ & 477 (64) & $<0.001$ \\
\hline & Not referred & & & & & 853 (65) & 0 & $274(37)$ & \\
\hline $\begin{array}{l}\text { Travel tim } \\
\text { to BCCA }\end{array}$ & $\leq 2$ hours & 1787 (69) & 1205 (83) & 582 (52) & $<0.001$ & 817 (62) & $\begin{array}{l}422 \\
(83)\end{array}$ & $548(73)$ & $<0.001$ \\
\hline
\end{tabular}




\section{Cureus}

centre

\begin{tabular}{|c|c|c|c|c|c|c|c|c|c|}
\hline & $>2$ hours & $501(20)$ & $243(17)$ & $258(23)$ & & $285(22)$ & $88(17)$ & $128(17)$ & \\
\hline & Unknown & $287(11)$ & 0 & $287(26)$ & & $212(16)$ & 0 & $75(10)$ & \\
\hline \multirow[t]{4}{*}{$\begin{array}{l}\text { Comorbidity } \\
\text { score }\end{array}$} & 0 & $1021(40)$ & $625(43)$ & 396 (35) & $<0.001$ & $525(40)$ & $\begin{array}{l}254 \\
(50)\end{array}$ & $242(32)$ & $<0.001$ \\
\hline & 1 & $152(6)$ & $94(7)$ & $58(5)$ & & $78(6)$ & 37 (7) & 37 (5) & \\
\hline & 2 & $836(33)$ & 474 (33) & $362(32)$ & & $392(30)$ & $\begin{array}{l}161 \\
(32)\end{array}$ & $283(38)$ & \\
\hline & $\geq 3$ & $566(22)$ & $255(18)$ & $311(28)$ & & $319(24)$ & $58(11)$ & $189(25)$ & \\
\hline \multirow[t]{4}{*}{$\begin{array}{l}\text { Nuclear } \\
\text { grade }\end{array}$} & 1 & $582(23)$ & $331(23)$ & $251(22)$ & $<0.001$ & $394(30)$ & $84(17)$ & 104 (14) & $<0.001$ \\
\hline & 2 & $767(30)$ & $528(37)$ & $239(21)$ & & $357(27)$ & $\begin{array}{l}197 \\
(39)\end{array}$ & $213(28)$ & \\
\hline & 3 & $636(25)$ & 441 (31) & 195 (17) & & $180(14)$ & $\begin{array}{l}195 \\
(38)\end{array}$ & 261 (35) & \\
\hline & Unknown & $590(23)$ & 148 (10) & $442(39)$ & & $383(29)$ & $35(7)$ & $173(23)$ & \\
\hline
\end{tabular}

Size of

primary

tumor

$236(48) \quad 737(51)$

tumor

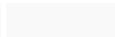

\begin{tabular}{|c|c|c|c|c|c|c|c|c|c|}
\hline & $1.6-4 \mathrm{~cm}$ & $634(25)$ & 452 (31) & $182(16)$ & & 210 (16) & $\begin{array}{l}193 \\
(38)\end{array}$ & 231 (31) & \\
\hline & $>4 \mathrm{~cm}$ & 309 (12) & 189 (13) & 120 (11) & & $101(8)$ & $32(6)$ & 176 (23) & \\
\hline & Unknown & 396 (15) & $70(5)$ & 326 (29) & & 245 (19) & $15(3)$ & 136 (18) & \\
\hline \multirow[t]{4}{*}{$\begin{array}{l}\text { Margin } \\
\text { status }\end{array}$} & $\begin{array}{l}\text { Negative } \geq 2 \\
\mathrm{~mm}\end{array}$ & 1785 (69) & 1150 (79) & 635 (56) & $<0.001$ & 827 (63) & $\begin{array}{l}390 \\
(77)\end{array}$ & 568 (76) & $<0.001$ \\
\hline & $\begin{array}{l}\text { Close }<2 \\
\mathrm{~mm}\end{array}$ & 271 (11) & $99(7)$ & 172 (15) & & 176 (13) & 45 (9) & $50(7)$ & \\
\hline & Positive & $268(10)$ & $125(9)$ & $143(13)$ & & 151 (12) & 66 (13) & $51(7)$ & \\
\hline & Unknown & 251 (10) & $74(5)$ & 177 (16) & & $160(12)$ & $9(2)$ & $82(11)$ & \\
\hline \multirow[t]{2}{*}{$\begin{array}{l}\text { Comedo } \\
\text { features }\end{array}$} & Absent & 1590 (62) & 837 (58) & 753 (67) & $<0.001$ & 956 (73) & $\begin{array}{l}252 \\
(49)\end{array}$ & 382 (51) & $<0.001$ \\
\hline & Present & 985 (38) & $611(42)$ & 374 (33) & & 358 (27) & $\begin{array}{l}258 \\
(51)\end{array}$ & 369 (49) & \\
\hline \multirow[t]{2}{*}{$\begin{array}{l}\text { Initial } \\
\text { treatment }\end{array}$} & BCS & 1314 (51) & $461(32)$ & 853 (76) & $<0.001$ & & & & \\
\hline & BCS + RT & $510(20)$ & 510 (35) & 0 & & & & & \\
\hline
\end{tabular}




\section{Cureus}

TABLE 1: Clinicopathologic characteristics of the entire cohort and comparisons by referral status and treatment type.

BCCA: British Columbia Cancer Agency; BCS: Breast conserving surgery; RT: Radiation therapy.

Compared to non-referred patients, referred patients had a non-significant trend for higher 10year ILRFS (96.3\% vs. 94.4\%, p = 0.07) (Figure $1 \mathrm{~A}$ ) and significantly higher 10-year BCSS (99.3\% vs. $97.1 \%, \mathrm{p}=0.001$ ) (Figure $1 B$ ), MFS (56.9\% vs. $51.7 \%, \mathrm{p}<0.001)$, and OS (91.4\% vs. $85.8 \%, \mathrm{p}<0.001)$.
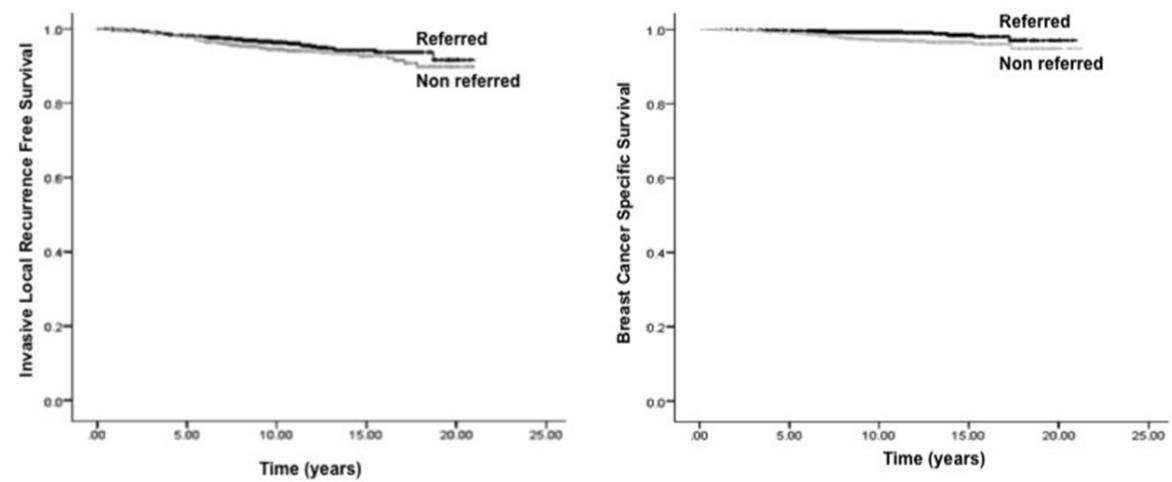

FIGURE 1: Comparisons of Kaplan-Meier. (A) Invasive local recurrence-free survival and $(B)$ breast cancer-specific survival by referral status.

\section{Comparisons of clinical characteristics and outcomes by treatment type}

During the study era, mastectomy use gradually decreased and post-BCS RT use increased. Women aged $>50$ years and women with increased comorbidities had higher rates of mastectomy, while women aged $>70$ years and women who lived more than two hours drive from a cancer centre were more likely to be treated with BCS alone (Table 1).

In cohorts treated with BCS alone vs. BCS + RT vs. mastectomy, 10-year outcomes were: ILRFS 93.7\% vs. 96.6\% vs. 97.7\%, (p<0.001), (Figure $2 A$ ); BCSS 97.6\% vs. 99.8\% vs. 98.6\%, (p = 0.01), (Figure $2 B$ ); and OS $86.5 \%$ vs. $93.5 \%$ vs. $90.1 \%$, ( $<<0.001)$. Ten-year MFS rates were lower in women treated with BCS alone compared to BCS + RT (72.2\% vs. 87.2\%), $(\mathrm{p}<0.001)$. 


\section{Cureus}
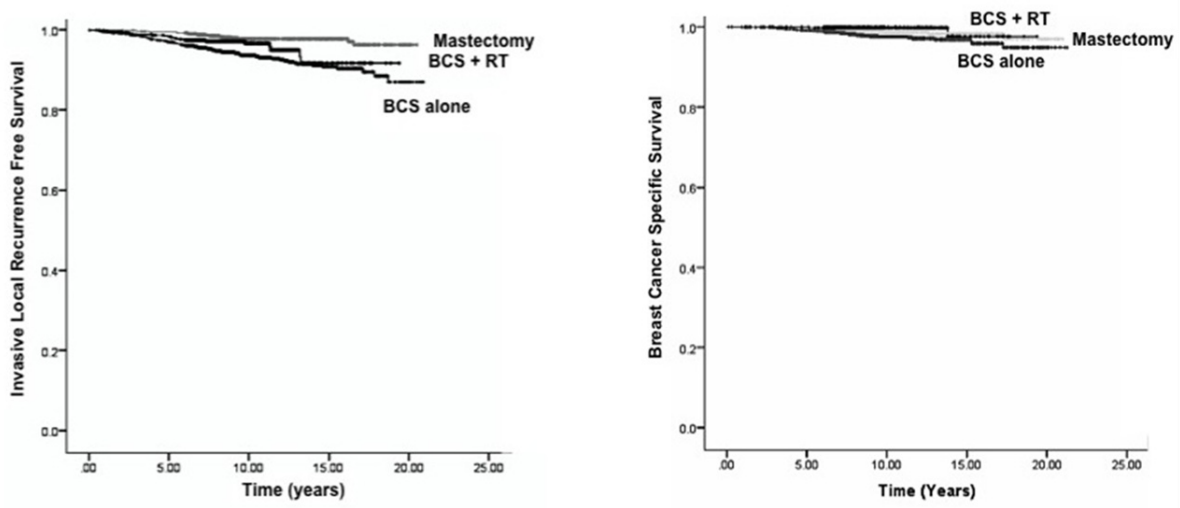

FIGURE 2: Comparisons of Kaplan-Meier. (A) Invasive local recurrence-free survival and (B) breast cancer-specific survival by treatment type.

Ten-year invasive local recurrence rates, stratified by clinicopathologic characteristics and treatment type are shown in Table 2. 


\section{Cureus}

\begin{tabular}{|c|c|c|c|c|c|}
\hline & & BCS alone & BCS + RT & Mastectomy & Log-rank p-value \\
\hline \multirow{4}{*}{ Age (years) } & $<50$ & $5(0.013)$ & $6(0.024)$ & $4(0.013)$ & 0.371 \\
\hline & $50-59$ & $9(0.018)$ & $1(0.008)$ & $0(0.000)$ & $<0.001$ \\
\hline & $60-69$ & $6(0.015)$ & $0(0.000)$ & $1(0.007)$ & $<0.001$ \\
\hline & $\geq 70$ & $5(0.013)$ & $3(0.021)$ & $4(0.018)$ & 0.428 \\
\hline \multirow{2}{*}{ Referral status } & Not referred & $6(0.009)$ & NA & $2(0.010)$ & 0.005 \\
\hline & Referred & $6(0.012)$ & $3(0.009)$ & $2(0.007)$ & $<0.001$ \\
\hline \multirow{4}{*}{ Comorbidity score } & 0 & $0.4(0.003)$ & $0(0.000)$ & $0.4(0.004)$ & 0.607 \\
\hline & 1 & $1(0.013)$ & $0(0.000)$ & $0(0.000)$ & 0.622 \\
\hline & 2 & $10(0.017)$ & $6(0.021)$ & $2(0.009)$ & $<0.001$ \\
\hline & $\geq 3$ & $12(0.020)$ & $7(0.036)$ & $5(0.017)$ & 0.003 \\
\hline \multirow{4}{*}{ Nuclear grade } & Grade 1 & $5(0.013)$ & $3(0.033)$ & $3(0.018)$ & 0.441 \\
\hline & Grade 2 & / (0.014) & $3(0.012)$ & $3(0.012)$ & 0.024 \\
\hline & Grade 3 & $7(0.021)$ & $2(0.009)$ & $2(0.011)$ & 0.002 \\
\hline & Unknown & $7(0.013)$ & $9(0.049)$ & $2(0.010)$ & 0.002 \\
\hline \multirow{4}{*}{ Size of primary tumor } & $\leq 1.5 \mathrm{~cm}$ & $7(0.010)$ & $2(0.012)$ & $3(0.011)$ & $<0.001$ \\
\hline & $1.6-4 \mathrm{~cm}$ & $8(0.020)$ & $3(0.013)$ & $2(0.011)$ & 0.003 \\
\hline & $>4 \mathrm{~cm}$ & $4(0.020)$ & $7(0.047)$ & $3(0.015)$ & 0.583 \\
\hline & Unknown & $5(0.015)$ & $7(0.064)$ & $0.8(0.008)$ & 0.004 \\
\hline \multirow{2}{*}{ Margin status } & Negative & $7(0.010)$ & $2(0.011)$ & $2(0.006)$ & $<0.001$ \\
\hline & Positive/close/unknown & $6(0.011)$ & $6(0.023)$ & $3(0.013)$ & 0.067 \\
\hline \multirow{2}{*}{ Comedocarcinoma } & Absent/unknown & $6(0.008)$ & $2(0.016)$ & $3(0.009)$ & 0.003 \\
\hline & Present & $8(0.015)$ & $4(0.012)$ & $2(0.008)$ & $<0.001$ \\
\hline
\end{tabular}

TABLE 2: Stratified analysis of 10-year invasive local recurrence rates (rate $\%$ (standard deviation)) by treatment type.

BCS: Breast conserving surgery; RT: Radiation therapy.

\section{Multivariable analysis}

On Cox regression analysis, factors associated with improved ILRFS were older age at diagnosis, low comorbidity score, absence of comedo histology, mastectomy, and post-BCS RT. Factors 
associated with improved BCSS were low comorbidity score, small tumor size, mastectomy, and post-BCS RT.

\section{Discussion}

The question of whether referral for oncologic assessment and treatment allocation affect outcome is the focus of the current report. Our analysis found that initial treatment type affected local recurrence, subsequent mastectomy rates, and survival outcomes for women with pure DCIS. In British Columbia, however, women who would like to undergo breast conserving therapy including RT need to be referred to one of the BCCA centres for assessment and treatment. While referral to a BCCA centre was not associated with higher ILRFS or BCSS, those women who were not referred experienced higher mastectomy rates and lower rates of adjuvant RT.

Women were more likely to be referred to one of the cancer centres if they were younger, have fewer comorbid conditions, and lived closer to a cancer centre. Similarly, in a study of 4139 women with DCIS diagnosed between 1998 and 2005, Krotneva, et al. reported that age and distance from a cancer centre influenced the probability of referral [17]. Our study showed that women referred after surgery were more likely to receive RT after BCS and experienced higher MFS, BCSS, and OS compared to non-referred women, despite having higher risk pathologic features. The improved outcomes may be attributed to not only better baseline health status, but may also be related to more complete assessment and treatment, as shown by the higher rates of clear margins and post-BCS RT use amongst those referred to a cancer centre.

In the current study, the rate of invasive local recurrence of two percent after mastectomy was similar to outcomes reported in other studies [18]. The rates of ILR after BCS alone or BCS + RT of $<10 \%$ were lower compared to data from randomized trials $\{6\}$, but similar to results from the lower risk arm of the recently published ECOG-ACRIN E5194 study of surgical excision without radiotherapy for low-risk breast patients [4]. The reasons for this observation are likely related to significant patient and treatment selection. Consistent with the literature, the rate of invasive recurrence was decreased by half with adjuvant radiotherapy in our study.

One concerning finding was the significantly lower ILRFS, BCSS, and OS among women with higher comorbidity scores, which persisted in multivariable modeling. Other studies have similarly observed that women with in situ and invasive breast cancer with comorbidities are treated less aggressively and have lower overall survival rates [19-21]. Some have also reported higher breast cancer mortality, even after controlling for other prognostic factors, such as stage and treatment [19-21]. In our study cohort, women with comorbidities were more frequently treated with mastectomy, and after controlling for differences in treatment, were still at higher risk for invasive local recurrence and breast cancer mortality. It appears that even in the setting of DCIS, patients with comorbidities should be assessed regarding definitive local therapy as other host or tumor biologic factors may be contributing to the observed poorer oncologic outcomes.

In the current multivariable analysis, factors associated with reduced risk of invasive local recurrence were older age at diagnosis, low comorbidity score, absence of comedonecrosis, mastectomy, and post-BCS RT. While these findings are consistent with other studies [22-23], these clinical factors were still not able to definitively discern those at very high or low risk of invasive recurrence. The Memorial Sloan Kettering Cancer Center developed a predictive model that estimates recurrence risk using factors such as age, use of RT, margin status, and a number of excisions [24], but independent evaluation of this model found suboptimal performance [25]. As reproducible models using purely clinical factors for DCIS risk prediction remain lacking, other methods such as the Oncotype DX DCIS score may prove useful in aiding clinicians to identify which patients will most benefit from which treatments [26-27]. 
The current study's findings should be interpreted in the context of its limitations and strengths. As the analysis is retrospective, there were inherent biases in patient and treatment selection. While central pathology review was not performed in the entire population, a proportion of patients would have had pathology review, and the results from this study and previous studies of these data found that prognostic factors relevant in the literature were also relevant in this dataset [22-23, 28]. The local recurrence outcome examined only included invasive recurrences, as all invasive recurrence would have been captured, but in situ recurrences were not recorded for all patients. In addition, our dataset lacked estrogen receptor status which impacts adjuvant hormone therapy use. Despite these limitations, the study contributes outcomes data in a large population-based cohort of women treated in a universal access health care system with long-term follow-up. While treatment decisions were made by the clinicians and patients, provincial guidelines updated over time and interdisciplinary tumor board conferences were available to guide decisions.

\section{Conclusions}

In this large population cohort, patients with DCIS referred for oncologic assessment were more likely to undergo post-BCS RT, resulting in lower rates of mastectomy and higher rates of survival compared to non-referred patients. Patients with comorbidities were less likely to be referred and were more likely to experience invasive recurrence and poorer BCSS. As DCIS is a complex but eminently curable disease, referral for multidisciplinary oncologic assessment after definitive surgery is warranted to discuss and individualize management for women with DCIS.

\section{Additional Information Disclosures}

Human subjects: Consent was obtained by all participants in this study. Informed consent obtained. Animal subjects: All authors have confirmed that this study did not involve animal subjects or tissue. Conflicts of interest: In compliance with the ICMJE uniform disclosure form, all authors declare the following: Payment/services info: All authors have declared that no financial support was received from any organization for the submitted work. Financial relationships: All authors have declared that they have no financial relationships at present or within the previous three years with any organizations that might have an interest in the submitted work. Other relationships: All authors have declared that there are no other relationships or activities that could appear to have influenced the submitted work.

\section{Acknowledgements}

This work was supported by the Canadian Breast Cancer Foundation, BC/Yukon Chapter and Canadian Breast Cancer Research Alliance (Grant \#015701). Neither of these agencies had any role in the study design; in the collection, analysis and interpretation of data; in the writing of the report; and in the decision to submit the article for publication.

\section{References}

1. Ernster VL, Barclay J, Kerlikowske K, et al.: Mortality among women with ductal carcinoma in situ of the breast in the population-based surveillance, epidemiology and end results program. Arch Intern Med. 2000, 160:953-958. 10.1001/archinte.160.7.953

2. Goodwin A, Parker S, Ghersi D, et al. : Post-operative radiotherapy for ductal carcinoma in situ of the breast. Cochrane Database Syst Rev. 2013, 11:CD000563.

10.1002/14651858.CD000563.pub7

3. Early Breast Cancer Trialists' Collaborative Group (EBCTCG), Correa C, McGale P, et al.: Overview of the randomized trials of radiotherapy in ductal carcinoma in situ of the breast . J Natl Cancer Inst Monogr. 2010, 2010:162-177. 10.1093/jncimonographs/lgq039 
4. Solin LJ, Gray R, Hughes LL, et al.: Surgical excision without radiation for ductal carcinoma in situ of the breast: 12-year results from the ECOG-ACRIN E5194 study. J Clin Oncol. 2015, 33:3938-3944. 10.1200/JCO.2015.60.8588

5. Wong JS, Kaelin CM, Troyan SL, et al.: Prospective study of wide excision alone for ductal carcinoma in situ of the breast. J Clin Oncol. 2006, 24:1031-1036. 10.1200/JCO.2005.02.9975

6. Wilkinson JB, Vicini FA, Shah C, et al.: Twenty-year outcomes after breast-conserving surgery and definitive radiotherapy for mammographically detected ductal carcinoma in situ. Ann Surg Oncol. 2012, 19:3785-3791. 10.1245/s10434-012-2412-5

7. Olivotto I, Levine M, The Steering Committee on Clinical Practice Guidelines for the Care and Treatment of Breast Cancer: Clinical Practice Guidelines for the Care and Treatment of Breast Cancer. Clinical practice guidelines for the care and treatment of breast cancer: The management of ductal carcinoma in situ (summary of the 2001 update). CMAJ. 2001, 165:912-913.

8. Allegra CJ, Aberle DR, Ganschow P, et al.: NIH state-of-the-science conference statement: diagnosis and management of ductal carcinoma in situ (DCIS). NIH Consens State Sci Statements. 2009, 26:1-27.

9. Moran MS, Bai HX, Harris EE, et al.: ACR appropriateness criteria $\left({ }^{\circledR}\right)$ ductal carcinoma in situ . Breast J. 2012, 18:8-15. 10.1111/j.1524-4741.2011.01197.x

10. Worni M, Akushevich I, Greenup R, et al.: Trends in treatment patterns and outcomes for ductal carcinoma in situ. J Natl Cancer Inst. 2015, 107:djv263. 10.1093/jnci/djv263

11. Wapnir IL, Dignam JJ, Fisher B, et al.: Long-term outcomes of invasive ipsilateral breast tumor recurrences after lumpectomy in NSABP B-17 and B-24 randomized clinical trials for DCIS. J Natl Cancer Inst. 2011, 103:478-488. 10.1093/jnci/djr027

12. Donker M, Litière $S$, Werutsky G, et al.: Breast-conserving treatment with or without radiotherapy in ductal carcinoma In Situ: 15-year recurrence rates and outcome after a recurrence, from the EORTC 10853 randomized phase III trial. J Clin Oncol. 2013, 31:40544059. 10.1200/JCO.2013.49.5077

13. Narod SA, Iqbal J, Giannakeas V, et al.: Breast cancer mortality after a diagnosis of ductal carcinoma in situ. JAMA Oncol. 2015, 1:888-896. 10.1001/jamaoncol.2015.2510

14. Chin-Lenn L, Craighead P, Bryant HE, et al.: Quality indicators for ductal carcinoma in situ (DCIS) of the breast: development using a multidisciplinary delphi process and its use in monitoring population-based treatment. J Surg Oncol. 2013, 108:348-351. 10.1002/jso.23401

15. Dragun AE, Huang B, Tucker TC, et al.: Disparities in the application of adjuvant radiotherapy after breast-conserving surgery for early stage breast cancer: impact on overall survival. Cancer. 2011, 117:2590-2598. 10.1002/cncr.25821.

16. Deyo RA, Cherkin DC, Ciol MA: Adapting a clinical comorbidity index for use with ICD-9-CM administrative databases. J Clin Epidemiol. 1992, 45:613-619.

17. Krotneva S, Reidel K, Verma A, et al.: Factors influencing the quality of local management of ductal carcinoma in situ: a cohort study. Curr Oncol. 2013, 20:e212-e222. 10.3747/co.20.1293

18. Boyages J, Delaney G, Taylor R: Predictors of local recurrence after treatment of ductal carcinoma in situ: a meta-analysis. Cancer. 1999, 85:616-628.

19. Land LH, Dalton SO, Jensen MB, et al.: Impact of comorbidity on mortality: a cohort study of 62,591 Danish women diagnosed with early breast cancer, 1990-2008. Breast Cancer Res Treat. 2012, 131:1013-1020. 10.1007/s10549-011-1819-1

20. Berglund A, Wigertz A, Adolfsson J, et al.: Impact of comorbidity on management and mortality in women diagnosed with breast cancer. Breast Cancer Res Treat. 2012, 135:281289. 10.1007/s10549-012-2176-4

21. Schonberg MA, Marcantonio ER, Li D, et al.: Breast cancer among the oldest old: tumor characteristics, treatment choices, and survival. J Clin Oncol. 2010, 28:2038-2045. 10.1200/JCO.2009.25.9796

22. Rakovitch E, Nofech-Mozes S, Narod S, et al.: Can we select individuals with low risk ductal carcinoma in situ (DCIS)? A population-based outcomes analysis. Breast Cancer Res. 2013, 138:581-590. 10.1007/s10549-013-2455-8

23. Shamliyan T, Wang SY, Virnig BA, et al.: Association between patient and tumor characteristics with clinical outcomes in women with ductal carcinoma in situ. J Natl Cancer Inst Monogr. 2010, 2010:121-129. 10.1093/jncimonographs/lgq034

24. Rudloff U, Jacks LM, Goldberg JI, et al.: Nomogram for predicting the risk of local recurrence after breast-conserving surgery for ductal carcinoma in situ. J Clin Oncol. 2010, 28:3762-3769. 


\section{Cureus}

\subsection{0/JCO.2009.26.8847}

25. Yi M, Meric-Bernstam F, Kuerer HM, et al.: Evaluation of a breast cancer nomogram for predicting risk of ipsilateral breast tumor recurrences in patients with ductal carcinoma in situ after local excision. J Clin Oncol. 2012, 30:600-607. 10.1200/JCO.2011.36.4976.

26. Rakovitch E, Nofech-Mozes S, Hanna W, et al.: A population-based validation study of the DCIS score predicting recurrence risk in individuals treated by breast-conserving surgery alone. Breast Cancer Res Treat. 2015, 152:389-398. 10.1007/s10549-015-3464-6

27. Solin LJ, Gray R, Baehner FL, et al.: A multigene expression assay to predict local recurrence risk for ductal carcinoma in situ of the breast. J Natl Cancer Inst. 2013, 105:701-710. 10.1093/jnci/djt067

28. Wai ES, Lesperance ML, Alexander CS, et al.: Predictors of local recurrence in a populationbased cohort of women with ductal carcinoma in situ treated with breast conserving surgery alone. Ann Surg Oncol. 2011, 18:1191-1124. 10.1245/s10434-010-1214-x 